Running title: LATERALITY AND TESTOSTERONE

\title{
Cerebral laterality for language is related to adult salivary testosterone levels but not digit ratio (2D:4D) in men: A functional transcranial Doppler ultrasound study
}

\section{Marietta Papadatou-Pastou ${ }^{\text {*a,b }}$ \& Maryanne Martin ${ }^{\mathrm{a}}$}

\author{
${ }^{\mathrm{a} C o g n i t i o n}$ and Health Research Group \\ Department of Experimental Psychology \\ University of Oxford, 9 South Parks Road, Oxford, OX1 3UD, UK \\ marietta.papadatou-pastou@seh.oxon.org \\ rose.martin@seh.ox.ac.uk
}

${ }^{b}$ Marietta Papadatou-Pastou is now at the Research Centre for Psychophysiology and Education, National and Kapodistrian University of Athens, Athens, Greece

*Address reprint requests to Dr. Marietta Papadatou-Pastou, Research Center for Psychophysiology and Education, National and Kapodistrian University of Athens, 27 Deinokratous Str, 10675 Athens, Greece.

Email: marietta.papadatou-pastou@ seh.oxon.org

Tel: +30 210 3641712; Fax: +302103614301 


\begin{abstract}
The adequacy of three competing theories of hormonal effects on cerebral laterality are compared using functional transcranial Doppler sonography (fTCD). Thirty-three adult males participated in the study (21 left-handers). Cerebral lateralization was measured by fTCD using an extensively validated word generation task. Adult salivary testosterone (T) and cortisol (C) concentrations were measured by luminescence immunoassay and prenatal $\mathrm{T}$ exposure was indirectly estimated by the somatic marker of 2 nd to 4 th digit length ratio (2D:4D). A significant quadratic relationship between degree of cerebral laterality for language and adult $\mathrm{T}$ concentrations was observed, with enhanced T levels for strong left hemisphere dominance and strong right hemisphere dominance. No systematic effects on laterality were found for cortisol or 2D:4D. Findings suggest that higher levels of T are associated with a relatively attenuated degree of interhemispheric sharing of linguistic information, providing support for the callosal and the sexual differentiation hypotheses rather than the Geschwind, Bahan and Galaburda (GBG) hypothesis.
\end{abstract}

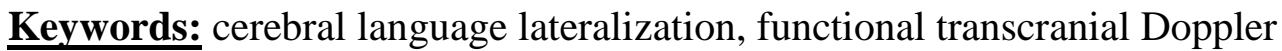
ultrasound (fTCD), word generation, testosterone, 2D:4D 
DOPPLER LATERALITY AND TESTOSTERONE

CEREBRAL LATERALITY FOR LANGUAGE IS RELATED TO ADULT SALIVARY TESTOSTERONE BUT NOT DIGIT RATIO (2D:4D) IN MEN: A FUNCTIONAL TRANSCRANIAL DOPPLER ULTRASOUND STUDY

\section{Introduction}

Individual differences in neurological organisation, including individual differences in cerebral laterality for language, are of key importance for deepening our understanding of the intact brain and its functions (Papadatou-Pastou, 2011). Prenatal sex hormones, such as testosterone (T), have been suggested to influence the development of cerebral laterality for language and its biological concomitant, handedness, but findings remain inconclusive (e.g., Hampson \& Sankar, 2012; Hollier, Maybery, Keelan, Hickey, \& Whitehouse, 2014; Lust et al., 2011; Papadatou-Pastou, Martin, \& Mohr, 2016). The most influential theories of hormonal effects on cerebral laterality for language and handedness are three classical formulations. These are the Geschwind, Behan and Galaburda (GBG) hypothesis (Galaburda, Corsiglia, Rosen, \& Sherman, 1987; Geschwind \& Behan, 1982; Geschwind \& Galaburda, 1985a, 1985b, 1985c, 1987; Rosen, Sherman, \& Galaburda, 1991; Schachter, Ransil, \& Geschwind, 1987), the callosal hypothesis (Witelson, 1991; Witelson \& Nowakowski, 1991), and the sexual differentiation hypothesis (Hines \& Shipley, 1984; Levy \& Gur, 1980). All three hypotheses associate lateralization with prenatal $\mathrm{T}$ levels, but make different predictions about the effects prenatal $\mathrm{T}$ levels exhibit on the direction and the degree of lateralization.

The GBG hypothesis predicts that prenatal $\mathrm{T}$ exerts its action during a critical period of brain development and increases the probability of right-hemispheric dominance, resulting in a less strong lateralization of language and handedness or even acting as a source of left-handedness and atypical language dominance. The 
mother provides small quantities of masculinizing hormones via her adrenals and ovaries, but males are necessarily exposed to more prenatal $\mathrm{T}$ than females because it is produced by their own developing testes. Therefore, increased left-handedness and atypical language lateralization is more likely to be expected in men compared to women. The effects of $\mathrm{T}$ depend on the availability of free unbound hormone and on the sensitivity of target tissues. This hypothesis has been the most influential amongst hormonal theories of lateralization, but while some studies provide supporting evidence (e.g., Kelso, Nicholls, Warne, \& Zacharin, 2000), a number of others have failed to find such evidence (e.g., Berenbaum \& Denburg, 1995; Bryden, McManus, \& Bulman-Fleming, 1994; Obrzut, 1994; Previc, 1994).

The callosal hypothesis (Witeson, 1991;Witelson \& Nowakowski 1991) states that cerebral lateralization results from cell death and axonal pruning in the corpus callosum and the temporo-parietal cortex during foetal and neonatal development, and that this process is mediated, at least in part, by T. Manipulation of early levels of sex hormones has indeed been found to affect naturally occurring cell death (Arnold \& Breedlove, 1985). This means that increased foetal T activity will result in a smaller corpus callosum, decreased connectivity between the hemispheres, especially in the temporo-parietal region, and greater lateralization of cognitive functions (Witelson, 1991). These effects of prenatal $\mathrm{T}$ have been observed in males and not in females, in accord with findings that right-handed males have a smaller corpus callosum than left-handed and ambidextrous males (Habib et al., 1991; Witelson, 1985, 1989, but see also Beaton, 1997 and Luders et al., 2010, whose research does not support this hypothesis). The callosal hypothesis makes predictions about the degree and not direction of lateralization, namely that low prenatal $\mathrm{T}$ exposure acts towards a less strong cerebral lateralization for language and 
handedness, at least in males. Empirical support has been received from two animal studies (Denenberg, Fitch, Schrott, Cowell, \& Waters, 1991; Rosen, 1996), human studies on functional laterality (e.g., Cohen-Bendahan, Buitelaar, van Goozen, \& Cohen-Kettenis, 2004; Hollier, Maybery, Keelan, Hickey, \& Whitehouse, 2014) and a study on the organizational effects of foetal T on the corpus callosum (Chura et al., 2010).

The sexual differentiation hypothesis (Hines \& Shipley, 1984; Levy \& Gur,1980) is solely based on data observing differences between males and females, but does not make assumptions on the nature of these differences. For example, studies showed masculinization in animals when prenatally exposed to androgens (for a review, see Goy \& McEwen, 1980). In addition, the human male brain seems to be more asymmetrically organized than the human female brain, both for verbal and nonverbal functions (Annett, 1985; Bryden, 1988; McGlone, 1980), and there are more left-handed individuals in the male population compared to the female population (Papadatou-Pastou, Martin, Munafò, \& Jones, 2008). Thus, according to the sexual differentiation hypothesis, which is based on the above mentioned findings, increased prenatal $\mathrm{T}$ concentration could lead to increased left-handedness or to a less strong right handedness and to greater cerebral laterality for language (without making predictions about direction of language laterality).

We turn now to the issue of the assessment of prenatal hormone levels. Even though all three theories implicate prenatal hormonal levels, only a limited number of studies have directly measured prenatal hormones (for a review see PapadatouPastou, Martin, \& Mohr, 2016). The complexity of sampling amniotic fluid in order to measure prenatal $\mathrm{T}$, as well as the fact that such sampling may only reflect maternal levels (Reinisch \& Sanders, 1984) has led the bulk of research studies to the 
indirect collection of evidence for prenatal hormonal influences by other methods of research. These methods include (i) twin studies (e.g., Cohen-Bendahan, Buitelaar, van Goozen, \& Cohen-Kettenis, 2004; Elkadi, Nicholls, \& Clode, 1999; Ooki, 2006; Vuoksimaa, Eriksson, Pulkkinen, Rose, \& Kaprio 2010), which are based on the twin testosterone transfer hypothesis, according to which there is hormonal transfer between fetuses from the same pregnancy (Tapp, Maybery, \& Whitehouse, 2011), (ii) studies using clinical samples, such as individuals with disorders of sexual differentiation, for example congenital adrenal hyperplasia (CAH; Hampson, 2015; Helleday, Siwers, Martin, \& Hugdahl, 1994; Mathews et al., 2004; Nass et al., 1987; Plante, Boliek, Binkiewicz, \& Erly, 1996) and Kleinfelter syndrome males (Itti et al., 2003; van Rijn et al., 2008), (iii) studies with individuals exposed to abnormal concentrations of sex steroid hormones, such as diethylstilbestrol (DES), prenatally by the mother (e.g., Helleday, 1994; Reinisch \& Sanders, 1992; Scheirs \& Vingerhoets, 1995; Smith \& Hines, 2000), and (iv) studies using healthy adult participants. However, twins are not representative as they differ in their developmental environment from the general population. Further, with these clinical samples, it is impossible to differentiate between the effects of the hormonal environment and those of any gene abnormalities associated with the disorder. Moreover, such studies are not truly experimental, in that participants cannot be randomly assigned to the different groups.

The focus of the present study will thus be on healthy adult individuals, as our interest lies within the general population. Adult $\mathrm{T}$ concentrations are a valid tool for this kind of research, as individual differences in early life hormone concentrations are preserved over relatively long time periods, thus $\mathrm{T}$ differences obtained in adulthood are at least moderately representative of individual differences 
in early life T secretion (Jamison, Meier, \& Campbell, 1993). A high concordance in the production rate of $\mathrm{T}$ in adult monozygotic twins has been found (Meikle, Bishop, Stringham, \& West, 1988), with genetic factors estimated to account for over $80 \%$ of the variance in the production rate of T (Meikle et al., 1988). At least some of the same inherited physiological constrains may operate during early development, given that $\mathrm{T}$ concentration in foetal testes approach adult per-unit values (George, 1987). Although this approach allows only for limited inferences to be drawn regarding the prenatal hormonal environment, it is advantageous in that it allows for the direct measurement of T levels, the selection of considerably larger sample sizes, and for the specific recruitment of selected populations, such as left-handers (Moffat \& Hampson, 2000). Indeed, a number of studies have been conducted to investigate hormonal effects on laterality in healthy adult volunteers (for a review see Papadatou-Pastou et al., 2016). However, the picture is still not entirely clear.

One possible explanation is that previous studies have used only neuropsychological testing as means to measure cerebral laterality, such as dichotic listening tests (e.g., Gadea, Gomez, Gonzalez-Bono, Salvador, \& Espert, 2003; Moffat \& Hampson, 2000) and/or visual half-field tests (e.g., Hausmann, Becker, Gather, \& Gunturkun, 2002). Brain imaging techniques, on the other hand, are considered to directly measure underlying neuronal activity. Here, we use a relatively new brain imaging technique for measuring cerebral laterality, functional transcranial Doppler ultrasound (fTCD), which has not been used in psychoneuroendocrinological research to date.

Functional TCD involves placing probes on either side of the head and using ultrasound to measure blood flow in the middle cerebral arteries (MCAs). The 
cerebral blood flow velocity (CBFV) changes in the MCAs are taken to indicate the downstream increase of regional metabolic activity during a task. It is non-invasive, low-cost, relatively easy to administer, and it appears to be completely safe, even for young children (Bishop, Watt, \& Papadatou-Pastou, 2009; Deppe, Ringelstein, \& Knecht, 2004). Moreover, it is relatively insensitive to movement artifacts (Bishop et al., 2009) and can be easily repeated in a follow-up study (Knecht, Deppe, Ringelstein et al., 1998). Functional TCD's spatial resolution is rather poor, restricted to the basal artery territories, but it has excellent temporal resolution and provides continuous measurement of blood flow changes which are associated with functional cortical activation (Deppe, Flöel et al., 2000). A limitation is that some individuals lack an acoustic temporal bone window for insonation of the MCAs, in which case penetration of the skull by the ultrasound beam is not feasible and fTCD cannot be applied.

The most frequently used activation task for assessing language dominance with fTCD is the Word Generation task, which involves the silent production of words that begin with a given cue letter. Using this task, it has been possible to show reliable left hemisphere activation for language tasks in typical adults, as well as the expected higher rate of right hemisphere language dominance in left-handers (Basic et al., 2004; Knecht et al., 2000). Functional TCD by means of the Word Generation task has, moreover, given highly congruent results for the assessment of hemispheric lateralization with fMRI (Deppe, Knecht, Papke, Henningsen, \& Ringelstein, 1999; Deppe, Knecht et al., 2000; Somers et al., 2011). It has been further validated in determining hemispheric dominance for language by direct comparison with the Wada test. Moreover, significant test-retest reliability of fTCD has been shown using 
the Word Generation task (Knecht, Deppe, Ringelstein et al., 1998; Stroobant \& Vingerhoets, 2001).

Functional TCD adds to the perfusion-sensitive techniques of functional imaging (fMRI, PET, etc). These techniques are based on the fact that cerebral perfusion is closely coupled to cerebral metabolism and neural activation. In particular, changes in cerebral perfusion during cognitive tasks result in a more rapid CBFV in the feeding basal intracranial arteries compared with rest periods (Aasslid, 1987; Droste, Harders, \& Rastogi, 1989a, 1989b; Hartje, Ringelstein, Kistinger, Fabianek, \& Willmes, 1994; Rihs et al., 1995; Silvestrini, Letizia, Matteis, Troisi, \& Caltagirone, 1994; Silvestrini, Troisi, Matteis, Cupini, \& Caltagirone, 1995). In fMRI and PET studies, lateralization is usually determined by calculating the difference between the activated brain regions in the left and the right hemisphere relative to the sum of all activated regions in both hemispheres. The fTCD provides identical information in a more efficient way, by directly comparing the relative blood flow velocity changes in the two MCAs. The quantitative measurements obtained by fTCD are moreover not biased by defining variable statistical thresholds, as is often the case in the analysis of fMRI data. The typical sensitivity in fTCD studies for detecting perfusion asymmetries between two basal arteries is of the order of $1 \%$ (Deppe, Knecht, Ebner et al., 1997; Knecht, Deppe, Ebner et al., 1998).

Apart from reliance only on neuropsychological testing as a means to measure cerebral laterality, another explanation for the discrepancy among research studies of hormonal effects on cerebral laterality may lie in the measurement of hormonal concentrations. Here we measure adult $\mathrm{T}$ via the collection of saliva samples, and not blood samples like some previous studies (e.g., Hausmann et al., 2002), as salivary $\mathrm{T}$ directly represents that fraction of $\mathrm{T}$ that is biologically active 
and available to tissue for metabolic purposes and, unlike bound $\mathrm{T}$, it can pass the blood-brain barrier and thereby potentially influence cognitive processing ( Plenis \& Baczek, 2010; Shute, Pellegrino, Hubert, \& Reynolds, 1983; Vermulen \& Verdonck, 1972). This makes salivary T optimal for research in behavioural endocrinology. Good documentation on the reliability, precision, accuracy, and analytical recovery of immunoassays designed to measure salivary $\mathrm{T}$ is available (Granger, Schwartz, Booth, \& Arentz, 1999). In addition, collecting saliva samples is painless and noninvasive, while it is straightforward enough to allow researchers and participants to perform collections themselves with minimal training (Plenis \& Baczek, 2010).

Previous studies have opted for measuring hormonal concentration in the morning, rather than in the afternoon, (e.g., Moffat \& Hampson, 1996, 2000). This should preferably be avoided, on two grounds: (a) hormonal concentrations are changing rapidly in the morning and (b) the morning peak is highly dependent on sleeping habits, even though it disappears rather quickly (Sanders et al., 2002). Thus, specimen collection during the afternoon and early evening is recommended for studies measuring individual differences in T (Yang, Hooven, Boynes, Gray, \& Pope, 2007). In Papadatou-Pastou et al. (2016) testing started at either 3 pm or 4:30 pm. In the present study we have improved our methodology by having a constant time for saliva collection, with all samples collected at 5.00 p.m. and 5.15 p.m. Moreover, circannual T rhythms were carefully controlled, as all testing took place within a month. Salivary cortisol (C) was also measured as a control hormone in order to be able to test for the specificity of any obtained relationships with language lateralization to T. Cortisol was chosen because it is another saliva steroid that displays similar diurnal variation (Kirschbaum \& Hellhammer, 1994a, 1994b). 
Salivary $\mathrm{T}$ effects have been observed on a smaller scale for females compared to males (e.g., Moffat \& Hampson, 2000), in line with all the hormonal theories presented above, which make stronger predictions for males. A number of explanations could be proposed for this sex difference. Firstly, $\mathrm{T}$ is present in smaller quantities in the female foetus and thus it may have less pronounced effects on cerebral asymmetry. In addition, the assessment of salivary $\mathrm{T}$ concentrations has been found to be less accurate in females than in males (Shirtcliff, Granger, \& Likos, 2002; Taieb et al., 2003). Moreover, T concentrations are considerably more stable over time for males than females (Granger, Shirtcliff, Booth, Kivlighan, \& Schwartz, 2004), suggesting that the probability of detecting significant T-behaviour relationships may be lower in females than in males (Granger et al., 2004). Furthermore, $\mathrm{T}$ concentrations in males show greater variability from one male to another, which increases the potential sensitivity of the study (Mercure, Ashwin, Dick, Halit, Auyeung, Baron-Cohen, et al., 2009). In the light of these considerations, only male participants were recruited in the present study. In addition to the measurement of adult $\mathrm{T}$ concentrations, the present study sets out to measure prenatal levels of $\mathrm{T}$ by means of a somatic marker for prenatal $\mathrm{T}$, the second to fourth digit length ratio (2D:4D; Beech \& Beauvois, 2005; Manning, Scutt, Wilson, \& Lewis-Jones, 1998; Sanders, Sjodin, \& deChastelaine, 2002). The 2D:4D has been long known to be sexually dimorphic (Baker, 1888; George, 1930) with males on average having lower ratios than females (Phelps, 1952). Digit length is under the control of the Homebox or Hox genes which also control the differentiation of the testes and ovaries (Peichel, Prabhakaran, \& Vogt, 1997); thus the functioning of the latter may be reflected in the formation of the former (Manning et al., 1998). Patterns of 2D:4D have been therefore suggested as somatic 
markers of gonadal function, such as the production of $\mathrm{T}$ and estrogen, in utero (Manning et al., 2000; Manning et al., 1998). Indeed, in adults, the 2D:4D length ratio is correlated negatively with $\mathrm{T}$ in males and positively with estrogen in both sexes (Manning et al., 1998).

Manning and colleagues have collected ample evidence for the relationship of the 2D:4D with sex hormones (e.g., Lutchmaya, Baron-Cohen, Raggati, Knichmeyer, \& Manning, 2004; Manning, 2002; Manning, Baron-Cohen, Wheelwright, \& Sanders, 2001; Manning, Bundred, Newton, \& Flanagan, 2003; Manning \& Taylor, 2001; Manning, Trivers, Singh, \& Thornhill, 1999). With regards to laterality, a number of studies have been conducted on the relationship of the 2D:4D and handedness as manifested by hand preference and hand skill (Beaton et al., 2011; Fink, Manning, Neave, \& Tan, 2004; Jackson, 2008; Manning \& Peters, 2009; Stoyanov, Marinov, \& Pashalieva, 2009). With regard to functional laterality, Bourne (2004) and Bourne and Gray (2009) found that lower 2D:4D ratios are associated with stronger right hemisphere dominance as measured by emotional chimeric faces and landmark tasks. In addition, Kalmady et al. (2013) reported an association of 2D:4D with lateralization on a spatial working memory task measured by fMRI.

The limited literature that exists on the relationship between $\mathrm{T}$ levels and cerebral laterality for language has used either (i) participants for whom researchers had access to amniotic fluid T (Grimshaw et al., 1993, 1995; Mercure et al., 2009; Lust, Geuze, Van de Beek, Cohen-Kettenis, Groothuis, \& Bouma, 2010) or umbilical cord serum T (Hollier et al., 2014) and were thus unselected for handedness resulting in samples of more right-handed than left-handed participants, (ii) right-handed only twins (Cohen-Bendahan et al., 2004), or (iii) samples that included equal or almost equal numbers of right- and left-handers with the aim of achieving a range of degrees 
of cerebral lateralization (Gadea et al., 2003; Moffat \& Hampson, 1996, 2000). However, since approximately $4 \%$ of right-handers but $27 \%$ of left-handers are right hemisphere dominant for language, samples with fewer or even equal numbers of left-handers might obscure relationships with cerebral lateralization for language, as they might not offer enough variance when it comes to language dominance. In the present study recruitment of participants was aimed specifically at left-handers and resulted in the number of left-handers being almost double that of right-handers.

The present study has been designed to investigate the relationship between $\mathrm{T}$ levels and cerebral laterality for language assessed by means of fTCD, as well as the relationship between $\mathrm{T}$ levels and handedness. A secondary aim has been to complement the measurement of adult $\mathrm{T}$ levels with another indirect measurement of prenatal $\mathrm{T}$ levels, the recently proposed somatic marker 2D:4D. Lower T levels are expected to be found in right-handers compared to left-handers according to the GBG and the sexual differentiation hypotheses (the callosal hypothesis does not make predictions for direction of handedness). The degree of handedness for both right- and left-handers is expected to be lower with elevated levels of $\mathrm{T}$ according to the GBG hypothesis and the sexual differentiation hypothesis, but higher according to the callosal hypothesis. With regards to cerebral lateralization for language, it is expected to be stronger in individuals with higher levels of $\mathrm{T}$ according to the corpus callosum and the sexual differentiation hypothesis and less strong according to the GBG hypothesis. Only the latter hypothesis makes a prediction with respect to direction, namely, that right-hemispheric dominance will be associated with higher $\mathrm{T}$ levels. It is hypothesized that any relationships found will be specific to $\mathrm{T}$ and will not generalize to $\mathrm{C}$.

\section{Method}




\subsection{Participants}

Thirty-three male participants took part in the present study (12 right-handers as assessed by means of the Edinburgh Handedness Inventory; Oldfield, 1971). They were all undergraduate or graduate students enrolled in the University of Oxford ( mean age $=23$ years, $S D=3$, range $=19-33$ ). Participants had already undergone screening when they were originally recruited for the study described in PapdatouPastou et al, (2016). They were thus native, monolingual English speakers with normal or corrected visual acuity. Before being enrolled in the follow-up it was checked that they were not on any medication that affects the central nervous system during the 6 months that proceeded the testing and that they were still neurologically intact. Two potential participants were seen but excluded from the sample, because sonography was not possible due to inadequate ultrasonographic penetration of the skull by the ultrasound beam (one case) or the data were too noisy (one case). One further participant was excluded from the analysis, as there was no sample in the test tubes for both the $\mathrm{T}$ samples and the single sample provided for the salivary $\mathrm{C}$ analysis was contaminated with blood and unsuitable for analysis. Participants were reimbursed for their time with cash (£15). The study was reviewed by and received ethics clearance through the Central University Research Ethics Committee (CUREC) of the University of Oxford.

\subsection{Assessment of language lateralization}

2.2.1. Apparatus: Bilateral blood flow was measured using a commercially available Doppler ultrasonography device (DWL Multidop T2: manufacturer, DWL Elektronische Systeme, Singen, Germany), using two 2-MHz transducer probes mounted on a flexible headset. 
2.2.2. Word Generation task: The Word Generation task was administered as described by Knecht et al. (1998). Participants were seated in front of a computer screen and two probes were attached to their heads using an elastic headband. In order to focus their attention on the task, the participants were presented with a cueing tone five seconds before a letter appeared on the screen for $2.5 \mathrm{~s}$. The language task consisted of silently bringing to mind as many words as possible starting with the displayed letter. After a secondary auditory signal following $15 \mathrm{~s}$ after the presentation of the letter, the participants had to say aloud the words they had retrieved. This way, task compliance was monitored (i.e., it was checked that participants were indeed using the 15 -s period to generate pertinent words, albeit it is possible that some of the words were generated only during the recall period). All words (or as many as possible) had to be reported within a 5-s time period. The next letter was presented in the same way after a relaxation period of $35 \mathrm{~s}$. The letters were presented in a random order and no letter was displayed more than once. Twenty-three trials corresponding to 23 letters of the alphabet were presented.

\subsection{FTCD data collection and analysis}

The right and left MCAs were insonated at the optimal depth for each participant $(45-56 \mathrm{~mm})$ with two transducer probes $(2 \mathrm{MHz})$ attached to a flexible headband and placed at the temporal skull windows bilaterally. The angles of insonation were adjusted to obtain the maximal signal intensity. ${ }^{1}$ Visual stimuli

\footnotetext{
1 The fTCD measurement of the CBFV is dependent on the angle of insonation (Bartels \& Flugel, 1994). Changes of this angle from $0^{\circ}$ to $30^{\circ}$ can result in differences in the calculated, absolute CBFV in the magnitude of $15 \%$ between examinations or sides. Also, in a narrowed arterial segment incidentally insonated during the test, the absolute velocity increase in blood flow due to cerebral activation would be greater than in a regular segment. This is why flow velocities used for statistical analyses were normalised. Flow velocities at rest were set as zero baseline and CBFV changes during the activated state were expressed as values in
} 
(letters) were presented on a computer controlled by Presentation software (Neurobehavioural Systems), which sent marker pulses to the Multi-Dop system to mark the start of each epoch.

Data were analysed using AVERAGE software, with the data being processed using the Autoedit function of Average 1.85, which downsamples the blood flow envelope from each probe to $25 \mathrm{~Hz}$, adds a channel corresponding to the heart beat, normalises the left and right cerebral blood flow velocity curve to a mean of $100 \%$, and removes heart beat activity using the heart cycle integration described by Deppe et al. (1997b). Artefacts like those elicited by probe displacement were then automatically detected by comparison of the number of pulses per time unit of the entire recording session with the frequency of peaks in a given segment. Frames of recording were rejected when the frequencies of peaks differed by more than one third between the entire recording and the given segment. Additionally, epochs containing CBFV values outside the range of $30 \%$ to $200 \%$ of the mean velocity were rejected, as these represent unusually low or high levels of activity and thus correspond to nonphysiological data (Deppe et al., 1997b). The remaining data were segmented into epochs that were time-linked to the cueing tone (on a total of 23 trials), and were then averaged. The epochs were set to begin $18 \mathrm{~s}$ before and to end $36 \mathrm{~s}$ after the cueing tone. The mean velocity in the 18 -s precueing interval was taken as the baseline value. An fTCD laterality index (LI) was then calculated following Deppe et al. (2004). The period of interest for verbal processing was 10-18 s after cuing and the integration interval was $2 \mathrm{~s}$. All participants had at least 15 valid epochs (Bishop, Badcock, \& Holt, 2010).

percentages relative to this baseline. The use of relative CBFV values eliminated the variability associated with changes in insonation angle or vessel diameter. 
Differences in the velocity changes in the two MCAs in every participant were statistically evaluated by the Wilcoxon test for each time point. This nonparametric test is less sensitive to outliers when only a limited number of epochs can be averaged. If the test cannot find any significant differences in the blood flow velocities, the value " 0 "' is returned. If the velocity in the left artery is significantly larger than in the right artery, the test returns the value " +1 "' and in the opposite case the value " -1 ",

\subsection{Hormonal assessment}

2.4.1. Salivary hormones: Participants provided two 1-ml samples of saliva for $\mathrm{T}$ assay, as well as two 1-ml samples for salivary $\mathrm{C}$ assay. The participants gave two saliva samples at 5 p.m. and two more at 5.15 p.m. on the same day as the testing (the researchers called each participant at that time to ensure saliva collection was made on time). Since participants had to provide the samples on their own after the testing had finished, they were given a saliva kit consisting of four test tubes (Salicaps), parafilm (to chew if necessary for saliva stimulation), a stirring stick, an instructions sheet, a bag to put the test tubes in, and an envelope to place the bag inside. They were asked to store the samples in their refrigerators overnight and return them to the researcher the following morning. The samples were frozen upon collection at $-80{ }^{\circ} \mathrm{C}$ until being sent off on dry ice for assay to the Biophysical Analysis Unit, Northumbria University. ${ }^{2}$ All testing was carried out within a month. 2.4.2. $2 D: 4 D$ length ratio: The length of the second and fourth digit of both the left and the right hand was measured in the ventral surface of the hand from the tip of the

2 Saliva samples for steroid measurement may be stored 7 days at room temperature, four weeks at $2-8^{\circ} \mathrm{C}$ and for longer periods at $<-20^{\circ} \mathrm{C}$ (Gröschl, Wagner, Rauh, \& Dörr, 2001). 
finger to the basal crease using a vernier caliper which measured to the nearest .01 $\mathrm{mm}$.

\subsection{Assays}

Luminescence immunoassay (LIA) was used to measure the levels of T and C in the saliva samples. Each sample was assayed twice. The $\mathrm{T}$ and $\mathrm{C}$ luminescence kits were supplied by IBL-Harburg. Luminescence was measured using a Bio-Tek FLx800 microplate reader used with kC4 Data Analysis Software (supplied by Labtech International Ltd.). Prior to determination, the frozen samples were thawed and centrifuged for 10 minutes at $3000 \mathrm{~g}$ to remove particulate material. Hormonal determinations were performed by an experienced Bioassay technician (Biophysical Analysis Unit, Northumbria University), who was unaware of the hypothesis under test.

\subsection{Assessment and scoring of handedness}

The 10-item Edinburgh Handedness Inventory (EHI, Oldfield, 1971) was used to assess the handedness of the participants. The EHI is short, simple, and has been widely used in the laterality literature, providing a good base for comparison between studies. Items include writing, drawing, throwing, scissors, toothbrush, knife (without a fork), spoon, broom (upper hand), striking match (match), and opening a box (lid). A five-point graded response format was used as suggested by PapadatouPastou, Martin, and Munafò (2013), whereby participants were asked to choose among the following options: If they always use one hand to perform the described activity, they were asked to circle $\mathrm{Ra}$ or La (for right always and left always). If they usually use one hand, they were asked to circle $\mathrm{Ru}$ or $\mathrm{Lu}$ (for usually right or usually left), as appropriate. If they use either hand, they were asked to circle Ei (for either). The score was calculated by giving a value of 0 to an "always left", 1 to a 
"usually left", 2 to a "both equally", 3 to a "usually right", and a value of 4 to an "always right" response. For each participant, we summed the scores for all items, divided this sum by the maximum score and multiplied this value by 100 . Thus, we obtained individual laterality index (LI) scores that ranged from 0 (extreme lefthandedness) to 100 (extreme right-handedness). All participants with scores above 70 were considered right-handers, whereas the rest were considered left-handers.

\subsection{Procedure}

Participants were asked to sit in the chair provided and were given the choice to watch the first few minutes of a movie on a portable DVD player, while the probes were being placed in position. The fTCD data were collected for the Word Generation task and then finger length was measured. Finally, participants were given the saliva kit and were instructed on how to provide the samples. Participants thus collected saliva samples unsupervised when they returned home after testing, but this was not considered a threat to the validity of the measurement, as the procedure is easy. Testing was carried out over a period of one month at either 10 a.m., 12 p.m., or 2 p.m., but all the saliva samples were given at 5 p.m. and 5.15 p.m in order to minimise the influence of circadian and circannual rhythms on $\mathrm{T}$ and $\mathrm{C}$ secretion.

\subsection{Statistical analyses}

Functional data were analysed using the Average software for Windows, which has been developed for the analysis of fTCD data (Deppe, Knecht, Henningsen, \& Ringelstein, 1997). Further analyses were performed using the Statistical Package for the Social Sciences (SPSS) version 23. The split-half reliability for the fTCD task was computed by correlating the LI values for odd and even epochs. The Kolmogorov-Smirnov $Z$ test was used to assess whether LIs in 
right- and left-handers were drawn from different populations, as well as whether hormonal levels of right- and left-hemisphere language dominant participants and of right- and left-handers were drawn from different populations, as the sample sizes of the compared groups were not appropriate for parametric testing. Unlike the parametric $t$-test for independent samples or the Mann-Whitney $U$ test, which test for differences in the location of two samples (differences in means and differences in average ranks, respectively), the Kolmogorov-Smirnov $Z$ test is sensitive to differences in the general shape of the distributions in the two samples, that is differences in dispersion and skewness (Spence, Cotton, Underwood, \& Duncan, 1990). The relationship between hormonal levels and degree of language lateralization was estimated using curve estimation regressions. Hormonal measurements (i.e., 2D:4D and salivary $\mathrm{T}$ and $\mathrm{C}$ concentrations) were the dependent variables and the degree of language lateralization the independent variable. Correlations between 2D:4D and salivary $\mathrm{T}$ and $\mathrm{C}$ concentrations were assessed using Pearson's $r$. All $p$-values were two-tailed and the $\alpha$-level was set at .05 .

\section{Results}

The overall distribution of cerebral lateralization for language revealed seven participants $(21.2 \% ; 2$ right-handers and 5 left-handers) being right-hemisphere language dominant and 26 participants $(78.8 \% ; 10$ right-handers and 16 left-handers) being left-hemisphere language dominant (see Figure 1), with participants with LIs < 0 being considered right-hemisphere language dominant and participants with LI $>0$ being considered left-hemisphere dominant. When applying the Wilcoxon test, five participants $(15.2 \%$; 2 right-handers and 3 left-handers) were found to be righthemisphere language dominant, four participants $(12.12 \%$; 2 right-handers and 2 left- 
handers) were found to process language bilaterally and 24 participants $(72.7 \% ; 8$ right-handers and 16 left-handers) were found to be left-hemisphere dominant for language.

The distribution of language lateralization was equivalent in right- and lefthanders, $Z=.66, p=.78$. The mean index of language dominance was 1.98 (range $=$ $-4.94,5.79, S D=2.89)$ for right-handers and $2.48($ range $=-2.88,6.68, S D=2.90)$ for left-handers. The split-half reliability for the fTCD task was .86 .

Insert Figure 1 about here

One participant (left-handed) was excluded from $\mathrm{C}$ analysis, as his $\mathrm{C}$ concentration was an outlier. Mean T concentration was $259.44 \mathrm{pmol} / \mathrm{l}$, (range $=$ $64.58-576.50, S D=109.75)$ and mean $\mathrm{C}$ concentration was $5.30 \mathrm{nmol} / \mathrm{l}($ range $=$ $.54-15.16, S D=3.34)$.

\subsection{Adult hormones and cerebral laterality for language}

The mean $\mathrm{T}$ concentration for right-hemispheric dominant participants was $203.89 \mathrm{pmol} / \mathrm{l}($ range $=139.58-236.67, S D=44.90)$ and for left- hemispheric dominant participants was $277.51 \mathrm{pmol} / 1$ (range $=64.58-576.50, S D=119.37)$. The mean $\mathrm{C}$ concentration for right-hemispheric dominant participants was 4.56 $\mathrm{nmol} / \mathrm{l}($ range $=0.54-7.48, S D=2.56)$ and for left- hemispheric dominant participants was $5.48 \mathrm{nmol} / \mathrm{l}$ (range $=1.54-15.16, S D=3.52)$.

In order to assess whether hormonal levels of right- and left-hemisphere language dominant participants were drawn from different populations, the Kolmogorov-Smirnov test was run separately with $\mathrm{T}$ and $\mathrm{C}$ concentrations as the dependent variables and with direction of language lateralization (right or left) as the 
fixed factor. A significant difference was found for T concentration in right- and lefthemisphere dominant participants, $Z=1.45, p=.031$, with the dispersion of $\mathrm{T}$ concentration being greater in left-hemisphere dominant participants compared to right-hemisphere dominant participants (see Figure 2). No significant difference was detected for $\mathrm{C}$ concentrations, $Z=.57, p=.89$.

To test the hypothesis that there is a relationship between degree of language lateralization and hormonal levels curve estimation regressions were run separately with $\mathrm{T}$ and $\mathrm{C}$ concentrations as the dependent variables and with the fTCD LI as the fixed factor. A U-shaped relationship was detected (see Figure 3), $F(30)=5.98, p=$ .007 , the best-fitting relation being: $\mathrm{T}=5.75(\mathrm{fTCD} \mathrm{LI})+3.84(\mathrm{fTCD} \mathrm{LI})^{2}+195.61$. No relationship was detected between fTCD LI and C concentrations, $F(28)=1.13$, $p=.34$.

We repeated the two analyses above excluding the right-hemisphere language dominant participants, as concerns have been voiced that they might represent atypical environmental and hormonal environments. Our results were unaffected, with a U-shaped relationship detected for the relationship between degree of language lateralization and hormonal levels, $F(23)=5.19, p=.014$, the best-fitting relation being: $T=-83.99(f T C D L I)+15.56(f T C D L I)^{2}+335.97$, and no relationship detected between fTCD LI and C concentrations, $F(22)=1.00, p=.39$.

Insert Figures 2 and 3 about here

\subsection{Adult hormones and handedness}

The mean $\mathrm{T}$ concentration for right-handers was $252.27 \mathrm{pmol} / \mathrm{l}$ (range $=$ $64.58-447.41, S D=107.87)$ and for left-handers $270.20 \mathrm{pmol} / \mathrm{l}(\mathrm{range}=106.08-$ 
576.50, $S D=117.36$ ). The mean $\mathrm{C}$ concentration for right-handers was $4.31 \mathrm{nmol} / \mathrm{l}$ $($ range $=.54-9.58, S D=2.56)$ and for left-handers $5.93 \mathrm{nmol} / \mathrm{l}($ range $=1.54-$ $15.16, S D=3.75)$.

In order to assess whether hormonal levels of right- and left-handers were drawn from different populations, the Kolmogorov-Smirnov test was run separately with $\mathrm{T}$ and $\mathrm{C}$ concentrations as the dependent variables and with direction of handedness (right or left) as the fixed factor. No differences were found for $\mathrm{T}$ concentrations, $Z=.63, p=.83$, or for $C$ concentrations, $Z=.83, p=.49$, between right- and left-handed participants.

To test the hypothesis that there is a relationship between degree of handendess and hormonal levels, curve estimation regressions were run separately with $\mathrm{T}$ and $\mathrm{C}$ concentrations as dependent variables and EHI score as fixed factor, but no significant relationships were detected for either $\mathrm{T}$ or $\mathrm{C}$ (all $p>.54$ ).

\subsection{D:4D ratio and cerebral laterality for language}

In the present sample, the mean 2D:4D for the right hand was .97 (range $=$ $.91-1.05, S D=.03)$ and for the left hand $.97($ range $=.88-1.03, S D=.03)$. These values are within the normal range (Manning et al., 2000). The 2D:4D length ratio was not correlated with $\mathrm{T}$ concentrations for either hand, nor was it correlated with the difference between the digit ratios of the right and left hands $\mathrm{D}_{\mathrm{R}-\mathrm{L}}$ (all $p>.43$ ), contrary to what was expected. To test the hypothesis that there is a relationship between degree of language lateralization and hormonal levels, curve estimation regressions were run separately with the right and left hand 2D:4D length ratios and the $D_{R-L}$ as the dependent variables and with the fTCD LI as the fixed factor, but no significant relationships were detected for either hand (all $p>.54$ ).

\section{4. $2 D: 4 D$ ratio and handedness}


To test the hypothesis that there is a relationship between degree of handedness and hormonal levels, curve estimation regressions were run separately with the right and left hand 2D:4D length ratios and the $\mathrm{D}_{\mathrm{R}-\mathrm{L}}$ as the dependent variables and with the EHI score as the fixed factor, but no significant relationships were detected for either hand (all $p>.14$ ).

\section{Discussion}

The aim of the present study was to investigate the relationship between cerebral lateralization for language, handedness, and salivary adult $\mathrm{T}$ levels, as well as 2D:4D. Lateralization was assessed by means of fTCD using the Word Generation task. As far as we are aware, this is the first study to examine the relation between salivary hormonal levels and cerebral laterality using fTCD.

Findings indicate that higher $\mathrm{T}$ concentrations are associated with a higher degree of lateralization in a sample of adult males. A significant quadratic relation indicated that participants with a stronger degree of hemisphere dominance for language (either left or right) had considerably higher T levels than individuals presenting more symmetrical patterns of laterality. Moreover, the dispersion of $\mathrm{T}$ concentration was found to be greater in left-hemisphere dominant participants compared to right-hemisphere dominant participants. No associations were found with $\mathrm{C}$, which was used as a control hormone. Lastly, no association were found between handedness and either $\mathrm{T}$ or $\mathrm{C}$ levels. The theoretical perspectives proposed for the association between adult $\mathrm{T}$ levels and functional asymmetries by the callosal hypothesis and the sexual differentiation hypothesis both fit the present data. Both hypotheses would predict a higher degree of lateralization related to higher $\mathrm{T}$ levels, while the Geschwind and Galaburda hypothesis suggests an opposite pattern. 
However, the absence of any significant association between handedness and hormonal levels does not provide support for the predictions of any of the three theories, and is discussed further.

With regard to the 2D:4D, no significant associations were found between language laterality and right 2D:4D, left 2D:4D or their difference. Similarly, there were no significant correlations between right or left 2D:4D and adult salivary T levels or handedness. This failure to demonstrate the expected results further adds to work by Grouios and colleagues, who have similarly failed to find expected relationships of the 2D:4D length ratio to conditions such as body weight (Koidou et al., 2006), sporting excellence (Grouios, Koidou, \& Kollias, 2007), and intellectual disability (Ypsilanti et al., 2008). It has indeed been pointed out that very strong inconsistencies and contradiction are to be found in the 2D:4D literature on sex differences in mathematical and spatial ability (Valla \& Ceci, 2011). It is possible that similar significant inconsistencies may be found in other areas of 2D:4D research. It might be the case that the 2D:4D might not be as useful as a biomarker of prenatal $\mathrm{T}$ levels as previously suggested. It is also possible that the $2 \mathrm{D}: 4 \mathrm{D}$ is not sensitive enough to reliably detect association with laterality measures with samples of the sizes of the present study. As an illustration, previous studies that have shown relationships with handedness measures have employed samples of 93 participants (Fink et al., 2004), 360 participants (Jackson, 2008) and over 170,000 participants (Manning \& Peters, 2009) (but also see Beaton et al., 2011, Stoyanov et al., 2009 who had smaller sample sizes). The lack of correlation between handedness and salivary $\mathrm{T}$ levels or handendess and 2D:4D might further be due to the fact that both are indirect measures of prenatal $\mathrm{T}$, and therefore both carry noise in their 
measurement. A study that has just been published, also failed to find an association between 2D:4D and cerebral lateralisation using fTCD (Hudson \& Hodgson, 2016).

Negative findings with regard to salivary $\mathrm{T}$ were recently published by our group (Papadatou-Pastou, Martin, \& Mohr, 2016) for both handedness and cerebral lateralization of language. The present study adds to the lack of findings with regards to handedness, a lack similarly reported by other studies (Beaton et al., 2011; McKeever et al., 1987; Vuoksimaa et al., 2010). However, associations of cerebral lateralization for language with salivary $\mathrm{T}$ were obtained here. We believe that this could be attributed to a number of methodological factors, including the optimization we introduced to the saliva collection method by having all saliva samples collected within a period of one month, at the same time in the early evening for all participants. It may moreover be attributed to the direct measurement of cerebral lateralization, which was assessed here by means of fTCD using the Word Generation task, a valid and reliable method. In neuropsychological tests, such as the dichotic listening and the visual half-field lexical decision tasks used by PapadatouPastou et al. (2016), on the other hand, cerebral lateralization is inferred indirectly from perceptual asymmetries, which may be influenced by factors other than true differences in cerebral dominance (Sommer, Aleman, Bouma, \& Kahn, 2004). Furthmore, including only male participants might have increased the sensitivity of the study, as (i) $\mathrm{T}$ is present in smaller quantities in the female foetus, (ii) the assessment of salivary $\mathrm{T}$ levels is more accurate in males compared to females (Shirtcliff, Granger, \& Likos, 2002; Taieb et al., 2003), (iii) T concentrations are more stable over time for males than females (Granger, Shirtcliff, Booth, Kivlighan, \& Schwartz, 2004), and (iv) T concentrations in males show greater variability (Mercure, Ashwin, Dick, Halit, Auyeung, Baron-Cohen, et al., 2009). 
Furthermore, in the present study the number of left-handers was nearly double that of right-handers, achieving a range of degrees of cerebral lateralization. It is possible that the present finding of significant evidence for hormonal effects on language lateralization is critically dependent upon the sensitivity of our procedure, which could account for previous failures to observe significant effects.

\section{Conclusions}

The present study reports a relation between adult $\mathrm{T}$ levels and brain lateralization for language in males. It provides an improvement on previous studies, both with regard to the measurement of language lateralization and with regard to the method of saliva collection. Further work on the relationship between hormonal levels and language lateralization could extend the investigation to female participants whose lateralization differs from that of male participants in at least one respect, that of the relative incidences of left- and right-handedness; there are relatively more left-handed males than females (Martin, Papadatou-Pastou, Jones, \& Munafò, 2010; Papadatou-Pastou et al., 2008; see also Jones \& Martin, 2010). Moreover, females may exhibit slightly different lateralization patterns within their menstrual cycle (e.g., Cacioppo et al., 2013), potentially allowing the investigation of intra-individual variation. In conclusion, the observed data fit well with the callosal hypothesis and sexual differentiation hypothesis, but not with the Geschwind and Galaburda hypothesis of hormonal effects on cerebral laterality for language. 


\section{AUTHOR NOTE}

This research was conducted while the first author was a doctoral student at the Department of Experimental Psychology, University of Oxford, UK. She was supported by the State Scholarship Foundation, Greece. It was carried out in the Oxford Study of Children's Communication Impairments (OSCCI) laboratory at the Department of Experimental Psychology, University of Oxford, led by Professor Dorothy Bishop to whom we are thankful for her support and useful advice on data collection and analysis. We would also like to thank Helen Watt for her assistance with data collection. 


\section{$\underline{\text { References }}$}

Aasslid, R. (1987). Visually evoked dynamic blood flow response of the human cerebral circulation. Stroke, 18, 771-775.

Amunts, K., Jancke, L., Mohlberg, H., Steinmetz, H., \& Zilles, K. (2000). Interhemispheric asymmetry of the human motor cortex related to handedness and gender. Neuropsychologia, 38, 304-312.

Annett, M. (1985). Left, right, hand and brain: The right shift theory. Hove: Lawrence Erlbaum Associates Ltd.

Arnold, A. P., \& Breedlove, S. M. (1985). Organizational and activational effects of sex steroids on brain and behavior: A reanalysis. Hormones and Behavior, 19, 469-498.

Baker, F. (1888). Anthropological notes on the human hand. American Journal of Anthropology, 1, 51-76.

Bartels, E., \& Flugel, K. A. (1994). Quantitative measurements of blood flow velocity in basal cerebral arteries with transcranial duplex color-flow imaging: a comparative study with conventional transcranial Doppler sonography. Journal of Neuroimaging, 4, 77-81.

Basic, S., Hajnsek, S., Poljakovic, Z., Basic, M., Culic, V., \& Zadro, I. (2004). Determination of cortical language dominance using functional transcranial Doppler sonography in left-handers. Clinical Neurophysiology, 115(1), 154160.

Beaton, A. A. (1997). The relation of planum temporale asymmetry and morphology of the corpus callosum to handedness, gender, and dyslexia: A review of the evidence. Brain and Language, 60(2), 255-322. 
Beaton, A. A., Rudling, N., Kissling, C., Taurines, R., \& Thome, J. (2011). Digit ratio (2D: 4D), salivary testosterone, and handedness. Laterality, 16(2), 136155.

Beech, J. R., \& Beauvois, M. W. (2006). Early experience of sex hormones as a predictor of reading, phonology, and auditory perception. Brain and language, 96(1), 49-58.

Berenbaum, S. A., \& Denburg, S. D. (1995). Evaluating the empirical support for the role of testosterone in the Geschwind-Behan-Galaburda model of cerebral lateralization: Commentary on Bryden, McManus and Bulman-Fleming. Brain and Cognition, 27(1), 79-83.

Bishop, D. V., Badcock, N. A., \& Holt, G. (2010). Assessment of cerebral lateralization in children using functional transcranial Doppler ultrasound (fTCD). JoVE (Journal of Visualized Experiments), (43), e2161-e2161.

Bishop, D. V. M., Watt, H., \& Papadatou-Pastou, M. (2009). An efficient and reliable method for measuring cerebral lateralization during speech with functional transcranial Doppler ultrasound. Neuropsychologia, 47, 587-590.

Bourne, V. J. (2014). Prenatal hormonal exposure (2D: 4D ratio) and strength of lateralisation for processing facial emotion. Personality and Individual Differences, 58, 43-47.

Bourne, V. J., \& Gray, D. L. (2009). Hormone exposure and functional lateralisation: Examining the contributions of prenatal and later life hormonal exposure. Psychoneuroendocrinology, 34(8), 1214-1221.

Bryden, M. P. (1988). Sex differences in cerebral organization: Real or imagined? Paper presented at the Tenth Annual Conference of the New York Neuropsychology Group, New York Academy of Sciences, New York. 
Bryden, M. P., McManus, I. C., \& Bulman-Fleming, M. B. (1994). Evaluating the empirical support for the Geschwind-Behan-Galaburda model of cerebral laterlization. Brain and Cognition, 26(2), 103-167.

Chura, L. R., Lombardo, M. V., Ashwin, E., Auyeung, B., Chakrabarti, B., Bullmore, E. T., \& Baron-Cohen, S. (2010). Organizational effects of fetal testosterone on human corpus callosum size and asymmetry. Psychoneuroendocrinology, $35(1), 122-132$.

Cohen-Bendahan, C. C. C., Buitelaar, J. K., van Goozen, S. H. M., \& CohenKettenis, P. T. (2004). Prenatal exposure to testosterone and functional cerebral lateralization: a study in same-sex and opposite-sex twin girls. Psychoneuroendocrinology, 29, 911-916.

Denenberg, V. H., Fitch, R. H., Schrott, L. M., Cowell, P. E., \& Waters, N. S. (1991). Corpuscallosum: Interactive effects of infantile handling and testosterone in the rat. Behavioral Neuroscience, 105(4), 562-566.

Deppe, M., Flöel, A., Knecht, S., Lohmann, H., Konrad, C., Sommer, J., et al. (2000). Temporal characteristics of cerebral blood flow velocity changes evoked by short-term visual stimulation. Neuroimage, 11(5, Part 2), S790.

Deppe, M., Knecht, S., Ebner, A., Huber, T., Jokeit, H., Ringelstein, E.-B., et al. (1997a). Determination of hemispheric language dominance: Reproducibility of assessment made by functional transcranial Doppler sonography. Neuroimage, 5(4), S587.

Deppe, M., Knecht, S., Henningsen, H., \& Ringelstein, E. B. (1997b). AVERAGE: a Windows $^{\circledR}$ program for automated analysis of event related cerebral blood flow. Journal of Neuroscience Methods, 75, 147-154. 
Deppe, M., Knecht, S., Papke, K., Henningsen, H., \& Ringelstein, E. B. (1999). Funktionelle TCD: Vergleich mit der funktionellen Magnetresonanztomographie. Klinische Neurophysiologie, 4, 292-298.

Deppe, M., Knecht, S., Papke, K., Lohmann, H., Fleischer, H., Heindel, W., et al. (2000). Assessment of hemispheric language lateralization: a comparison between fMRI and fTCD. Journal of Cerebral Blood Flow Metabolism, 20(2), 263-268.

Deppe, M., Ringelstein, E.-B., \& Knecht, S. (2004). The investigation of functional brain lateralization by transcranial Doppler sonography. NeuroImage, 21(3), 1124-1146.

Droste, D. W., Harders, A. G., \& Rastogi, E. (1989a). A transcranial Doppler study of blood flow velocity in the middle cerebral arteries performed at rest and during mental activities. Stroke, 20, 1005-1011.

Droste, D. W., Harders, A. G., \& Rastogi, E. (1989b). Two transcranial Doppler studies on blood flow velocity in both middle cerebral arteries during rest and the performance of cognitive tasks. Neuropsychologia, 27(10), 1221-1230.

Elkadi, S., Nicholls, M. E. R., \& Clode, D. (1999). Handedness in opposite and samesex dizygotic twins: testing the testosterone hypothesis. NeuroReport, 10, 333336.

Fink, B., Manning, J. T., Neave, N., \& Tan, U. (2004). Second to fourth digit ratio and hand skill in Austrian children. Biological Psychology, 67, 375-384.

Gadea, M., Gomez, C., Gonzalez-Bono, E., Salvador, A., \& Espert, R. (2003). Salivary testosterone is related to both handedness and degree of linguistic lateralization in normal women. Psychoneuroendocrinology, 28(3), 274-287. 
Galaburda, A. M., Corsiglia, J., Rosen, G. D., \& Sherman, G. F. (1987). Planum temporale asymmetry, reappraisal since Geschwind and Levitsky. Neuropsychologia, 25, 853-868.

George, R. (1930). Human finger types. Anatomical Records, 46, 199-204.

Geschwind, N., \& Behan, P. (1982). Left-handedness: Association with immune disease, migraine, and developmental learning disorder. Proceedings of the National Academy of Sciences, 79(16), 5097-5100.

Geschwind, N., \& Galaburda, A. M. (1985a). Cerebral lateralization -Biological mechanisms, associations, and pathology: I. A hypothesis and a program for research. Archives of Neurology, 42, 428-459.

Geschwind, N., \& Galaburda, A. M. (1985b). Cerebral lateralization -Biological mechanisms, associations, and pathology: II. A hypothesis and a program for research. Archives of Neurology, 42, 521-552.

Geschwind, N., \& Galaburda, A. M. (1985c). Cerebral lateralization -Biological mechanisms, associations, and pathology: III. A hypothesis and a program for research. Archives of Neurology, 42, 634-654.

Geschwind, N., \& Galaburda, A. S. (1987). Cerebral lateralization: Biological mechanisms, associations, and pathology. Cambridge, MA: MIT Press.

Geschwind, D. H., Gregg, J., Boone, K., Karrim, J., Pawlikowska-Haddal, A., Rao, E., ... \& Rappold, G. A. (1998). Klinefelter's syndrome as a model of anomalous cerebral laterality: testing gene dosage in the $\mathrm{X}$ chromosome pseudoautosomal region using a DNA microarray. Developmental Genetics, 23(3), 215-229.

Goy, R. W., \& McEwen, B. S. (1980). Sexual differentiation of the brain. London: Oxford University Press. 
Granger, D. A., Schwartz, E. B., Booth, A., \& Arentz, M. (1999). Salivary testosterone determination in studies of child health and development. Hormones and Behavior, 35, 18-27.

Granger, D. A., Shirtcliff, E. A., Booth, A., Kivlighan, K. T., \& Schwartz, E. B. (2004). The "trouble" with salivary testosterone. Psychoneuroendocrinology, $29,1229-1240$.

Grimshaw, G. M., Bryden, M. P., \& Finegan, J. K. (1993). Relations between prenatal testosterone and lateralization at age 10. Journal of Clinical and Experimental Neuropsychology, 15, 39-40.

Grimshaw, G. M., Bryden, M. P., \& Finegan, J. K. (1995). Relations between prenatal testosterone and cerebral lateralization in children. Neuropsychology, 9(1), 68-79.

Gröschl, M., Wagner, R., Rauh, M., \& Dörr, H. G. (2001). Stability of salivary steroids: the influences of storage, food and dental care. Steroids, 66, 737741.

Grouios, G., Koidou, I., \& Kollias, N. (2007). The second to fourth digit ratio in elite and non-elite male sport competitors, 12th European Congress of Sport Psychology. Halkidiki, Greece.

Habib, M., Gayraud, D., Oliva, A., Regis, J., Salamon, G., \& Khalil, R. (1991). Effects of handedness and sex on the morphology of the corpus callosum: A study with brain magnetic resonance imaging. Brain and Cognition, 16(1), $41-61$.

Hampson, E. (2015). The development of hand preference and dichotic language lateralization in males and females with congenital adrenal hyperplasia. Laterality: Asymmetries of Body, Brain and Cognition, 1-18. 
Hampson, E., \& Sankar, J. S. (2012). Hand preference in humans is associated with testosterone levels and androgen receptor gene polymorphism. Neuropsychologia, 50(8), 2018-2025.

Hartje, W., Ringelstein, E. B., Kistinger, B., Fabianek, D., \& Willmes, K. (1994). Transcranial Doppler ultrasonic assessment of middle cerebral artery blood flow velocity changes during verbal and visuospatial cognitive tasks. Neuropsychologia, 32(12), 1443-1452.

Hausmann, M., Becker, C., Gather, U., \& Gunturkun, O. (2002). Functional cerebral asymmetries during the menstrual cycle: a cross-sectional and longitudinal analysis. Neuropsychologia, 40, 808-816.

Helleday, J., Siwers, B., Ritzen, E. M., \& Hugdahl, K. (1994). Normal lateralization for handedness and ear advantage in a verbal dichotic listening task in women with congenital adrenal hyperplasia (CAH). Neuropsychologia, 32, 875-880.

Hollier, L. P., Maybery, M. T., Keelan, J. A., Hickey, M., \& Whitehouse, A. J. (2014). Perinatal testosterone exposure and cerebral lateralization in adult males: Evidence for the callosal hypothesis. Biological psychology, 103, 4853.

Hudson, J. M., \& Hodgson, J. C. (2016). Is digit ratio (2D: 4D) a reliable pointer to speech laterality?. Behavioural Brain Research, 301, 258-261.

Jackson, C. (2008). Prediction of hemispheric asymmetry as measured by handedness from digit length and 2D:4D digit ratio. Laterality: Asymmetries of Body, Brain and Cognition, 13(1), 34-50.

Jamison, C. S., Meier, R. J., \& Campbell, B. C. (1993). Dermatoglyphic asymmetry and testosterone levels in normal males. American Journal of Physiology and Anthropology, 90, 185-198. 
Jones, G. V., \& Martin, M. (2010). Language dominance, handedness and sex: Recessive X-linkage theory and test. Cortex, 46(6), 781-786.

Itti, E., Gaw Gonzalo, I. T., Boone, K. B., Geschwind, D. H., Berman, N., Pawlikowska- Haddal, A., ... \& Swerdloff, R. S. (2003). Functional neuroimaging provides evidence of anomalous cerebral laterality in adults with Klinefelter's syndrome. Annals of Neurology, 54(5), 669-673.

Kalmady, S. V., Agarwal, S. M., Shivakumar, V., Jose, D., Venkatasubramanian, G., \& Reddy, Y. J. (2013). Revisiting Geschwind's hypothesis on brain lateralisation: A functional MRI study of digit ratio (2D: 4D) and sex interaction effects on spatial working memory. Laterality: Asymmetries of Body, Brain and Cognition, 18(5), 625-640.

Kelso, W. M., Nicholls, M. E. R., Warne, G. L., \& Zacharin, M. (2000). Cerebral lateralization and cognitive functioning in patients with congenital adrenal hyperplasia. Neuropsychology, 14(3), 370-378.

Kirschbaum, C., \& Hellhammer, D. (1994a). Methodological aspects of salivary cortisol measurement. In C. Kirschbaum, G. Read \& D. Hellhammer (Eds.), Assessment of Hormones and Drugs in Saliva and Biobehavioral Research (pp. 19-25). Seattle, WA: Hogrefe \& Huber.

Kirschbaum, C., \& Hellhammer, D. (1994b). Salivary cortisol in psychoneuroendocrine research: recent developments and applications. Psychoneuroendocrinology, 19, 313-333.

Knake, S., Haag, A., Hamer, H. M., Dittmer, C., Bien, S., Oertel, W. H., \& Rosenow, F. (2003). Language lateralization in patients with temporal lobe epilepsy: a 
DOPPLER LATERALITY AND TESTOSTERONE

comparison of functional transcranial Doppler sonography and the Wada test. Neuroimage, 19(3), 1228-1232.

Knecht, S., Deppe, M., Dräger, B., Bobe, L., Lohmann, H., Ringelstein, E.-B., et al. (2000). Language lateralization in healthy right-handers. Brain 123, 74-81.

Knecht, S., Deppe, M., Ebner, A., Henningsen, H., Huber, T., Jokeit, H., et al. (1998). Non-invasive determination of language lateralization by functional transcranial Doppler sonography: A comparison with the Wada test. Stroke, 29(1), 82-86.

Knecht, S., Deppe, M., Ringelstein, E.-B., Wirtz, M., Lohmann, H., Dräger, B., et al. (1998). Reproducibility of functional transcranial Doppler sonography in determining hemispheric language lateralization. Stroke, 29, 1155-1159.

Koidou, I., Kollias, N., \& Grouios, G. (2006). Second to forth digit ratio in overweight and normal weight preadolescent girls: A preliminary investigation, 12th European Meeting of the International Association of Adolescent Health. Athens, Greece.

Levy, J., \& Gur, R. C. (1980). Individual differences in psychoneurological organization. In J. Herron (Ed.), Neuropsychology of left-handedness (pp. 199-210). New York: Academic Press.

Luders, E., Cherbuin, N., Thompson, P. M., Gutman, B., Anstey, K. J., Sachdev, P., \& Toga, A. W. (2010). When more is less: Associations between corpus callosum size and handedness lateralization. Neuroimage, 52(1), 43-49.

Lust, J. M., Geuze, R. H., Van de Beek, C., Cohen-Kettenis, P. T., Groothuis, A. G. G., \& Bouma, A. (2010). Sex specific effect of prenatal testosterone on language lateralization in children. Neuropsychologia, 48(2), 536-540. 
Lust, J. M., Geuze, R. H., Van de Beek, C., Cohen-Kettenis, P. T., Bouma, A., \& Groothuis, T. G. (2011). Differential effects of prenatal testosterone on lateralization of handedness and language. Neuropsychology, 25(5), 581.

Lutchmaya, S., Baron-Cohen, S., Raggati, P., Knichmeyer, R., \& Manning, J. T. (2004). 2nd to 4th digit ratios, fetal testosterone and estradiol. Early Human Development, 77(1-2), 23-28.

Manning, J. T. (2002). Digit ratio: a pointer to fertility, behaviour and health. New Jersey: Rutgers University Press.

Manning, J. T., Barley, L., Walton, J., Lewis-Jones, D. I., Trivers, R. L., Singh, D., et al. (2000). The 2nd:4th digit ratio, sexual dimorphism, population differences, and reproductive success: evidence for sexually antagonistic genes? Evolution and human Behaviour, 21, 163-183.

Manning, J. T., Baron-Cohen, S., Wheelwright, S., \& Sanders, G. (2001). The 2nd to 4th digit ratio and autism. Developmental Medicine and Child Neurology, 43, 160-164.

Manning, J. T., Bundred, P. E., Newton, D. J., \& Flanagan, B. F. (2003). The 2nd to 4th digit ratio and variation in the androgen receptor gene. Evolution and Human Behaviour, 24, 399-405.

Manning, J. T., \& Peters, M. (2009). Digit ratio (2D:4D) and hand preference for writing in the BBC Internet Study. Laterality, 14(5), 528-540.

Manning, J. T., Scutt, D., Wilson, J. D., \& Lewis-Jones, D. I. (1998). The ratio of 2nd to 4th digit length: a predictor of sperm number and concentrations of testosterone, luteinizing hormone and estrogen. Human Reproduction, 13(11), 3000-3004. 
Manning, J. T., \& Taylor, R. P. (2001). 2nd to 4th digit ratio and male ability in sport: implications for sexual selection in humans. Evolution and Human Behaviour, 22, 61-69.

Manning, J. T., Trivers, R. L., Singh, D., \& Thornhill, R. (1999). The mystery of female beauty. Nature, 399, 214-215.

Martin, M., Papadatou-Pastou, M., Jones, G. V. \& Munafò, M. (2010). Sex and location as determinants of handedness: reply to Vuoksimaa and Kaprio (2010). Psychological Bulletin, 136(3), 348-50.

Mathews, G. A., Fane, B. A., Pasterski, V. L., Conway, G. S., Brook, C., \& Hines, M. (2004). Androgenic influences on neural asymmetry: Handedness and language lateralization in individuals with congenital adrenal hyperplasia. Psychoneuroendocrinology, 29(6), 810-822.

McGlone, J. (1980). Sex differences in human brain asymmetry: a critical survey. Behavioral and Brain Sciences, 3, 215-263.

Meikle, A. W., Bishop, D. T., Stringham, J. D., \& West, D. W. (1988). Quantitating genetic and nongenetic factors that determine plasma sex-steroid variation in normal male twins. Metabolism, 35, 1090-1095.

Mercure, E., Ashwin, E., Dick, F., Halit, H., Auyeung, B., Baron-Cohen, S., et al. (2009). IQ, fetal testosterone and individual variability in children's functional lateralization. Neuropsychologia, 47(12), 2537-2543.

Moffat, S. D., \& Hampson, E. (1996). Salivary testosterone levels in left- and righthanded adults. Neuropsychologia, 34(3), 225-233.

Moffat, S. D., \& Hampson, E. (2000). Salivary testosterone concentrations in lefthanders: an association with cerebral language lateralization? Neuropsychology, 14(1), 71-81. 
Nass, R., Baker, S., Speiser, P., Virdis, R., Balsamo, A., Cacciari, E., et al. (1987). Left-hand bias in female congenital adrenal hyperplasia patients. Neurology, $37,711-715$.

Obrzut, J. E. (1994). The Geschwind-Behan-Galaburda theory of cerebral lateralization: Thesis, antithesis, and synthesis? Brain and Cognition, 26(2), $267-274$.

Oldfield, R. C. (1971). The assessment and analysis of handedness: the Edinburgh inventory. Neuropsychologia, 9(1), 97-113.

Ooki, S. (2006). Nongenetic factors associated with human handedness and footedness in Japanese twin children. Environmental health and preventive medicine, 11(6), 304-312.

Papadatou-Pastou, M. (2011). Handedness and language lateralization: Why are we right-handed and left- brained? Hellenic Journal of Psychology, 8, 248-265.

Papadatou-Pastou, M., Martin, M., \& Mohr, C. (2016). Salivary testosterone levels are unrelated to handedness or cerebral lateralization for language. Laterality: Asymmetries of Body, Brain and Cognition, 1-34.

Papadatou-Pastou, M., Martin, M., Munafò, M. R., \& Jones, G. V. (2008). Sex differences in left-handedness: A meta-analysis of 144 studies. Psychological Bulletin, 134, 677-699.

Papadatou-Pastou, M., Martin, M., \& Munafò, M. R. (2013). Measuring hand preference: A comparison among different response formats using a selected sample. Laterality: Asymmetries of Body, Brain and Cognition, 18(1), 68107. 
Peichel, C. L., Prabhakaran, B., \& Vogt, T. F. (1997). The mouse Ulnaless mutation deregulates posterior Hoxd gene expression and alters appendicular patterning. Development, 24, 3481-3492.

Phelps, V. R. (1952). Relative index finger length as a sex-influenced trait in man. American Journal of Genetics, 4, 72-89.

Plante, E., Boliek, C., Binkiewicz, A., \& Erly, W. K. (1996). Elevated androgen, brain development and language/learning disabilities in children with congenital adrenal hyperplasia. Developmental Medicine and Child Neurology, 38, 423-437

Previc, F. H. (1994). Assessing the legacy of the G-B-G model. Brain and Cognition, 26(2), 174-180.

Plenis, A., \& Baczek, T. (2010). Quantification of the salivary steroid hormones considered as bio-markers in clinical research studies and sports medicine. Current Pharmaceutical Analysis, 6(3), 182-197.

Reinisch, J. M., \& Sanders, G. (1984). Prenatal gonadal steroidal influences on gender-related behaviour. In G. J. De Vries, J. P. C. De Bruin, H. G. M. Uylings \& M. A. Corner (Eds.), Progress in brain research, vol 61, Sex differences in the brain. Amsterdam: Elsevier.

Reinisch, J. M., \& Sanders, S. A. (1992). Effects of prenatal exposure to diethylstilboestrol (DES) on hemipsheric laterliaty and spatial ability in human males. Hormones and Behavior, 26, 62-75.

Rihs, F., Gutbrod, K., Gutbrod, B., Steiger, H. J., Sturzenegger, M., \& Mattle, H. (1995). Determination of cognitive hemispheric dominance by "Stereo" transcranial Doppler sonography. Stroke, 26, 70-73.

Rosen, G. D. (1996). Cellular, morphometric, ontogenic and connectional substrates 
of anatomical asymmetry. Neuroscience and Behavioral Reviews, 20(4), $607-615$.

Rosen, G. D., Sherman, G. F., \& Galaburda, A. M. (1991). Ontogenesis of neocortical asymmetry: A [3H] thymidine study. Neuroscience, 41(2-3), $779-790$.

Ryan, B.C., Vandenbergh, J.G. (2002). Intrauterine position effects. Neuroscience and Biobehavioural Reviews, 26, 665-678.

Sanders, G., Sjodin, M., \& deChastelaine, M. (2002). On the elusive nature of sex differences in cognition: hormonal influences contributing to within-sex variation. Archives of Sexual Behavior, 31(1), 145-152.

Schachter, S. C., Ransil, B. J., \& Geschwind, N. (1987). Associations of handedness with hair color and learning disabilities. Neuropsychologia, 25(1B), 269-276.

Scheirs, J. G. M., \& Vingerhoets, A. J. J. M. (1995). Handedness and other laterality indices in women prenatally exposed to DES. Journal of clinical and experimental neuropsychology, 17(5), 725-730.

Shirtcliff, E. A., Granger, D. A., \& Likos, A. (2002). Gender differences in the validity of testosterone measured in saliva by immunoassay. Hormones and Behavior, 42, 62-69.

Shute, V. J., Pellegrino, J. W., Hubert, L., \& Reynolds, R. W. (1983). The relationship between androgen levels and human spatial abilities. Bulletin of the Psychonomic Society, 21, 465-468.

Silvestrini, M., Letizia, M., Matteis, M., Troisi, E., \& Caltagirone, C. (1994). Bilateral simultaneous assessment of cerebral flow velocity during mental activity. Journal of Cerebral Blood Flow Metabolism, 14, 643-648. 
Silvestrini, M., Troisi, E., Matteis, M., Cupini, L. M., \& Caltagirone, C. (1995). Involvement of the healthy hemisphere in recovery from aphasia and motor deficit in patients with cortical ischemic infarction: a transcranial Doppler study. Neurology, 45(10), 1815-1820.

Smith, L. L., \& Hines, M. (2000). Language lateralization and handedness in women prenatally exposed to diethylstilbestrol (DES). Psychoneuroendocrinology, 25(5), 497-512.

Sommer, I. E. C., Aleman, A., Bouma, A., \& Kahn, R. S. (2004). Do women really have more bilateral language representation than men? A meta-analysis of functional imaging studies. Brain, 127, 1845-1852.

Somers, M., Neggers, S. F., Diederen, K. M., Boks, M. P., Kahn, R. S., \& Sommer, I. E. (2011). The measurement of language lateralization with functional transcranial Doppler and functional MRI: a critical evaluation. Frontiers in human neuroscience, 5, 31 .

Spence, J. T., Cotton, J. W., Underwood, B. J., \& Duncan, C. P. (1990). Elementary statistics (5th ed.). Englewood Cliffs (NJ): Prentice Hall.

Stoyanov, Z., Marinov, M., \& Pashalieva, I. (2009). Finger length ratio (2D:4D) in left- and right-handed males. International Journal of Neuroscience, 119(7), 1006-1013.

Stroobant, N., \& Vingerhoets, G. (2001). Test-retest reliability of functional transcranial Doppler ultrasonography. Ultrasound in medicine \& biology, 27(4), 509-514.

Stroobant, N., Buijs, D., \& Vingerhoets, G. (2009). Variation in brain lateralization during various language tasks: a functional transcranial Doppler study. Behavioural Brain Research, 199(2), 190-196. 
Taieb, J., Mathian, B., Millot, F., Patricot, M.-C., Mathieu, E., Queyrel, N., et al. (2003). Testosterone measured by 10 immunoassays and by isotope-dilution gas chromatography-mass spectrometry in sera from 116 men, women and children. Endocrinology and metabolism, 49, 1381-1395.

Tapp, A. L., Maybery, M. T., \& Whitehouse, A. J. (2011). Evaluating the twin testosterone transfer hypothesis: a review of the empirical evidence. Hormones and Behavior, 60(5), 713-722.

van Rijn, S., Aleman, A., Swaab, H., Vink, M., Sommer, I., \& Kahn, R. S. (2008). Effects of an extra X chromosome on language lateralization: an fMRI study with Klinefelter men (47, XXY). Schizophrenia research, 101(1), 17-25.

Valla, J. M., \& Ceci, S. J. (2011). Can sex differences in science be tied to the long reach of prenatal hormones? Brain organization theory, digit ratio (2D/4D), and sex differences in preferences and cognition. Perspectives on Psychological Science, 6(2), 134-146.

Vermulen, A., \& Verdonck, L. (1972). Some studies on the biological significance of free testosterone. Journal of Steroid Biochemistry, 3, 421-426.

Vuoksimaa, E., Eriksson, C. P., Pulkkinen, L., Rose, R. J., \& Kaprio, J. (2010). Decreased prevalence of left-handedness among females with male co-twins: evidence suggesting prenatal testosterone transfer in humans?. Psychoneuroendocrinology, 35(10), 1462-1472

Wallentin, M. (2009). Putative sex differences in verbal abilities and language cortex: A critical review. Brain and language, 108(3), 175-183.

Witelson, S. F. (1985). The brain connection: The corpus callosum is larger in lefthanders. Science, 229(4714), 665-668.

Witelson, S. F. (1989). Hand and sex differences in the isthmus and genu of the 
human corpus callosum. A postmortem morphological study. Brain, 112(3), 799-835.

Witelson, S. F. (1991). Neural sexual mosaicism: sexual differentiation of the human temporo-pariental region for functional asymmetry. Psychoneuroendocrinology, 16, 131-153.

Witelson, S. F., \& Nowakowski, R. S. (1991). Left out axons make men right: A hypothesis for the origin of handedness and functional asymmetry. Neuropsychologia, 29, 327-333.

Yang, C. F. J., Hooven, C. K., Boynes, M., Gray, P. B., \& Pope, H. G. (2007). Testosterone levels and mental rotation performance in Chinese men. Hormones and behavior, 51(3), 373-378.

Ypsilanti, A., Ganou, M., Koidou, I., \& Gtouios, G. (2008). Digit ratio (2D:4D) in individuals with intellectual disability: Investigating the role of testosterone in the establishment of cerebral lateralization. Laterality, 13(6), 527-533. 
Figure 1. Bimodal distribution of hemispheric language lateralization as assessed by functional transcranial Doppler ultrasound (fTCD).

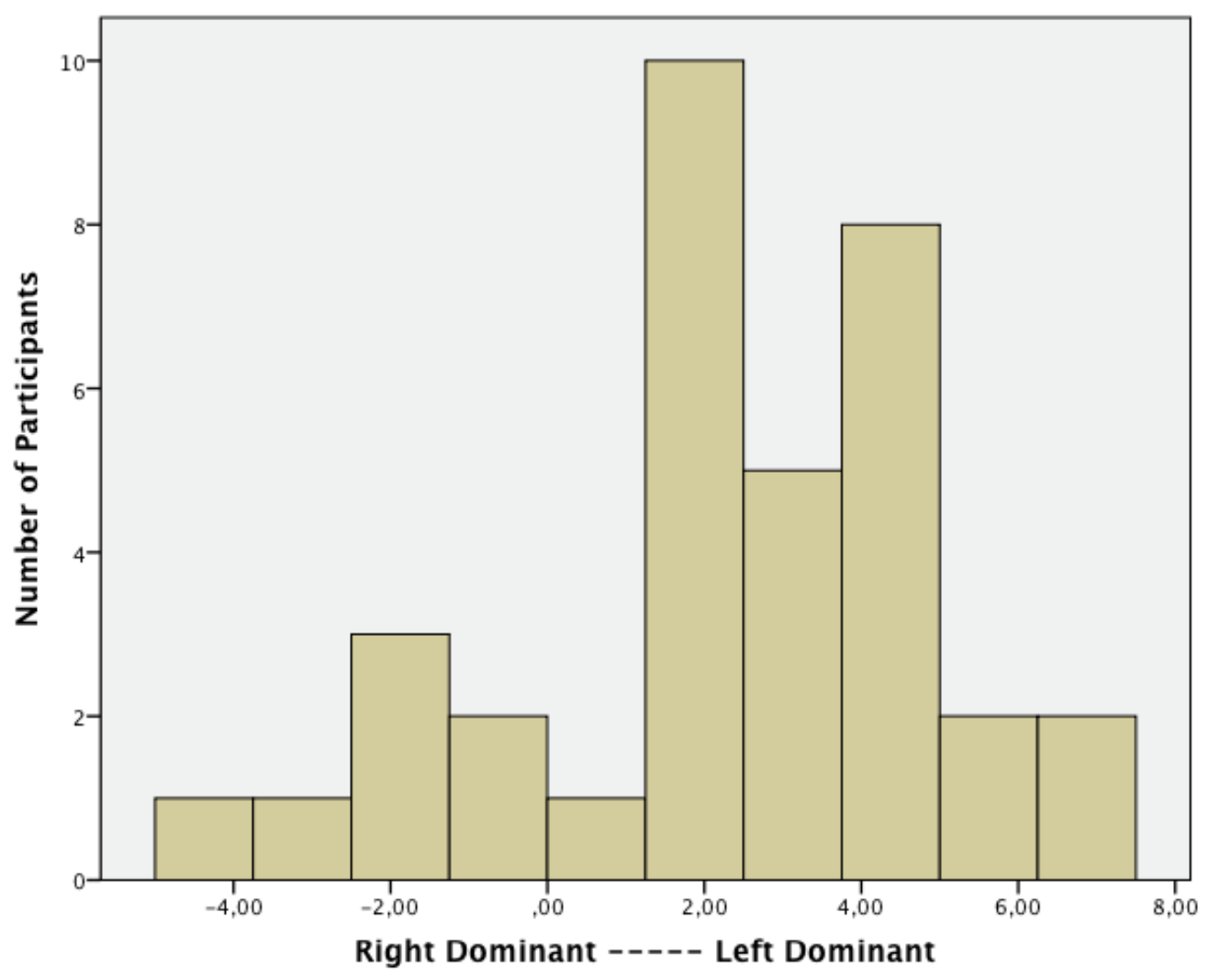


Figure 2. Distribution of hemispheric language lateralization as assessed by functional transcranial Doppler ultrasound (fTCD) in left-hemisphere dominant and righthemisphere dominant participants.

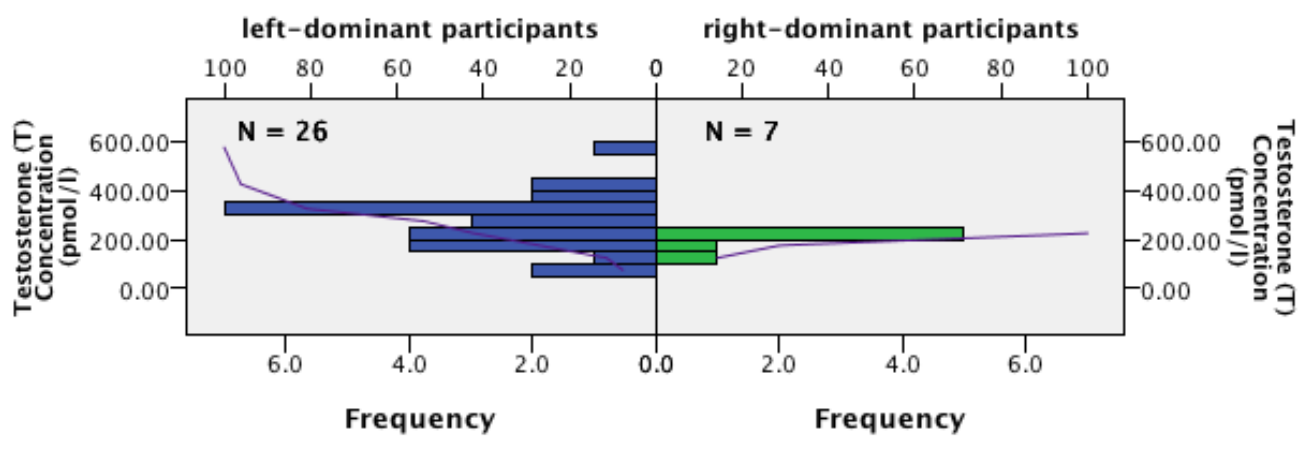

